\title{
BMJ Open Quality of clinical practice guidelines in delirium: a systematic appraisal
}

\author{
Shirley H Bush, ${ }^{1,2}$ Katie L Marchington, ${ }^{3}$ Meera Agar, ${ }^{4}$ Daniel H J Davis, ${ }^{5}$ \\ Lindsey Sikora, ${ }^{6}$ Tammy W Y Tsang ${ }^{2}$
}

To cite: Bush SH,

Marchington KL, Agar M, et al. Quality of clinical practice guidelines in delirium: a systematic appraisal. BMJ Open 2017;7: e013809. doi:10.1136/ bmjopen-2016-013809

- Prepublication history for this paper is available online. To view these files please visit the journal online (http://dx.doi.org/10.1136/ bmjopen-2016-013809).

Received 9 August 2016 Revised 13 January 2017 Accepted 20 February 2017

\section{(1) crossmatk}

${ }^{1}$ Division of Palliative Care, Department of Medicine, University of Ottawa, Ottawa, Ontario, Canada

${ }^{2}$ Bruyère Research Institute, Ottawa, Ontario, Canada

${ }^{3}$ Division of Palliative Care, Department of Family and Community Medicine, University of Toronto, Toronto, Ontario, Canada

${ }^{4}$ Centre for Cardiovascular and Chronic Care, Faculty of Health, University of Technology Sydney, Sydney, New South Wales, Australia ${ }^{5} \mathrm{MRC}$ Unit for Lifelong Health and Ageing, University College London, London, UK ${ }^{6}$ Health Sciences Library, University of Ottawa, Ottawa, Ontario, Canada

Correspondence to Dr Shirley H Bush; sbush@bruyere.org

\section{ABSTRACT}

Objective: To determine the accessibility and currency of delirium guidelines, guideline summary papers and evaluation studies, and critically appraise guideline quality.

Design: 1. Systematic literature search for formal guidelines (in English or French) with focus on delirium assessment and/or management in adults ( $\geq 18$ years), guideline summary papers and evaluation studies. 2. Full appraisal of delirium guidelines published between 2008 and 2013 and obtaining a 'Rigour of Development' domain screening score cutoff of $>40 \%$ using the Appraisal of Guidelines for Research and Evaluation (AGREE II) instrument.

Data sources: Multiple bibliographic databases, guideline organisation databases, complemented by a grey literature search.

Results: 3327 database citations and 83 grey literature links were identified. A total of 118 retrieved delirium guidelines and related documents underwent full-text screening. A final 21 delirium guidelines (with 10 being $>5$ years old), 12 guideline summary papers and 3 evaluation studies were included. For 11 delirium guidelines published between 2008 and 2013, the screening AGREE II 'Rigour' scores ranged from $3 \%$ to $91 \%$, with seven meeting the cut-off score of $>40 \%$. Overall, the highest rating AGREE II domains were 'Scope and Purpose' (mean 80.1\%, range 64-100\%) and 'Clarity and Presentation' (mean $76.7 \%$, range 3897\%). The lowest rating domains were 'Applicability' (mean 48.7\%, range 8-81\%) and 'Editorial Independence' (mean 53\%, range 2-90\%). The three highest rating guidelines in the 'Applicability' domain incorporated monitoring criteria or audit and costing templates, and/or implementation strategies.

Conclusions: Delirium guidelines are best sourced by a systematic grey literature search. Delirium guideline quality varied across all six AGREE II domains, demonstrating the importance of using a formal appraisal tool prior to guideline adaptation and implementation into clinical settings. Adding more knowledge translation resources to guidelines may improve their practical application and effective monitoring. More delirium guideline evaluation studies are needed to determine their effect on clinical practice.

\section{INTRODUCTION}

Delirium is a common neurocognitive disorder with the hallmark of disturbed

\section{Strengths and limitations of this study}

A strength of this study is the usage of an experienced university health sciences librarian to assist with the search strategy for the systematic literature search.

- A complement of four (rather than two) appraisers conducted the full Appraisal of Guidelines for Research and Evaluation (AGREE II) quality assessment of the delirium guidelines.

- It was not possible to retrieve the full text for all literature search citations.

- Language was restricted to English and French for the second-level screening.

- Two delirium guideline updates have been published since the initial literature search.

attention and awareness developing over a short period of time. ${ }^{1}$ Common predisposing risk factors for delirium are advanced age and dementia. Delirium prevalence in general medical hospital settings is 18$35 \%,{ }^{2}{ }^{3} 26-62 \%$ in palliative care units, ${ }^{4}$ and $30-70 \%$ in critical care, depending on the patient population and assessment methods. ${ }^{5}{ }^{6}$ Prevalence rates of up to $88 \%$ at the end of life (last hours to weeks of life) have been reported. ${ }^{4}$ However, the diagnosis of delirium is frequently missed or misdiagnosed in multiple clinical settings due to fluctuating symptoms and signs, in addition to a lack of routine cognitive screening and assessment of attention. ${ }^{2-12}$ Delirium causes functional impairment, increased falls, increased healthcare costs, prolonged hospitalisation with an increased risk of placement in long-term care at discharge and increased risk of mortality. ${ }^{13}{ }^{14}$ It worsens pre-existing dementia and increases the risk for developing de novo dementia. ${ }^{15}$ Delirium also causes significant psychological distress for patients, families and healthcare providers. ${ }^{16}$ It has been estimated that $\sim 30 \%$ of delirium episodes can be prevented and treated using multicomponent non-pharmacological strategies. $^{2}{ }^{17}$ Delirium is usually multifactorial in 
origin, and is potentially reversible if the identified precipitant/s are treatable. Although the current mainstay of delirium treatment is supportive non-pharmacological care, pharmacological treatment of delirium with antipsychotics has historically been used despite limited evidence for efficacy and concerns regarding their adverse effects, especially in patients with pre-existing dementia. ${ }^{18-23}$ It should also be noted that currently no antipsychotic has an official indication for delirium. Various pharmacological agents have also been trialled as delirium preventative strategies. ${ }^{2}{ }^{24}$ The multidimensional management of delirium requires interprofessional comprehensive care. With significant ongoing patient morbidity and healthcare costs due to delirium, there remains a pressing need to improve the overall management of this deleterious clinical syndrome for patients and their families.

Shaneyfelt stated that clinical practice guidelines should enhance healthcare quality and outcomes for many conditions. ${ }^{25}$ Guidelines may potentially assist clinicians with clinical care and decision-making, and provide standardisation of care delivery across disciplines within an institution as well as interinstitutional benchmarking. Clinical practice guidelines have been defined as 'systematically developed statements to assist practitioner and patient decisions about appropriate healthcare for specific clinical circumstances'. ${ }^{26}$ More recently, the Canadian Medical Association handbook on clinical practice guidelines stated that guidelines aim to 'summarise research findings and make clinical decisions more transparent' and 'identify gaps in knowledge and prioritise research activities'. ${ }^{27}$ Recently, authors have questioned the trustworthiness of guidelines. ${ }^{25} 28$ Only applicable, high-quality, rigorous, non-biased guidelines with valid recommendations should be selected by clinicians to adapt and implement into their clinical practice. ${ }^{29-31}$

Multiple clinical practice guidelines on delirium have been published despite a lack of high-level evidence for the management of delirium, with the result that many final guideline recommendations are derived from 'expert' opinion. ${ }^{32}$ Our previous non-systematic search for formal delirium guidelines demonstrated that guidelines were difficult to source using selected databases. ${ }^{32}$ We subsequently sought to determine and review rigorous national and international delirium guidelines that would be applicable for adaptation and implementation into a palliative care setting, as well as develop a sitespecific evaluation strategy. To the best of our knowledge, the quality and validity of published delirium guidelines have not been reported. To appraise their currency and accessibility, we conducted a systematic search for delirium guidelines published between 1990 and 2013. Using the Appraisal of Guidelines for Research and Evaluation (AGREE II) instrument, ${ }^{33}$ a critical assessment of the quality and validity of guidelines published from 2008 to 2013 was performed. In addition, guideline summaries and studies evaluating implemented guidelines were identified.
METHODS

\section{Data sources and searches}

A systematic literature search for existing delirium clinical practice guidelines for any clinical setting, summary papers and studies evaluating implemented guidelines was conducted in multiple electronic bibliographic databases by an information specialist librarian. The search for the Cochrane Library and the Database of Reviews of Effects (DARE), Medline (Ovid), EMBASE (Ovid), CINAHL, PsycINFO (Ovid) and TRIP (Turning Research into Practice) databases was executed on 16 August 2013 with no date limitations, and no language or age restriction. Search terms included 'delirium', 'guideline', 'health planning guideline', and 'Clinical protocols'. Box 1 shows the search strategy for Medline (Ovid).

For this project, we used the CAN-IMPLEMENT Resource, a detailed guideline adaptation and implementation planning resource that was developed by the Canadian Guideline Adaptation Study Group. As per CAN-IMPLEMENT recommendations, ${ }^{34}$ a search of guideline organisation databases, including the USA National Guideline Clearinghouse (NGC) ${ }^{35}$ and the Guidelines International Network (G-I-N) International Guideline Library, ${ }^{36}$ was also performed. Using the aforementioned search terms, a grey literature search was performed (between 9 May and 20 December 2013) through Google and Google Scholar, as well as reviewing the websites of relevant organisations, such as international delirium associations. Any possible documents related to delirium guidelines (such as summary versions and pathways) found on the grey literature search were retrieved. Supplemental hand searching for delirium guidelines was also conducted.

\section{Appraisal of Guidelines for Research and Evaluation II instrument (AGREE II)}

The AGREE II instrument appraises the quality of guidelines by focusing on the guideline development process, as opposed to formally evaluating the content of a guideline. It consists of 23 items in six distinct domains: 'Scope and Purpose', 'Stakeholder Involvement', 'Rigour of Development', 'Clarity and Presentation', 'Applicability' and 'Editorial Independence'. Each AGREE II item is scored on a 7-point scale from 1= strongly disagree to $7=$ strongly agree. An additional two global rating items at the end of AGREE II provide an overall assessment of the guideline. Domain 3 of AGREE II, the 'Rigour of Development' domain, has eight items and assesses the 'process of gathering and summarising the evidence, and methods used to develop recommendations' ${ }^{33}$ Within the 'Rigour of Development' domain, AGREE II item number 10 considers that 'the health benefits, side effects and risks have been considered in formulating the recommendations'. The 4-item Domain 5 , known as 'Applicability', 'pertains to the likely barriers and facilitators to implementation, strategies to improve uptake and resource implications of applying the guideline'. ${ }^{33}$ The online version of the AGREE II instrument 
Box 1 Methodology for systematic appraisal of delirium clinical practice guidelines

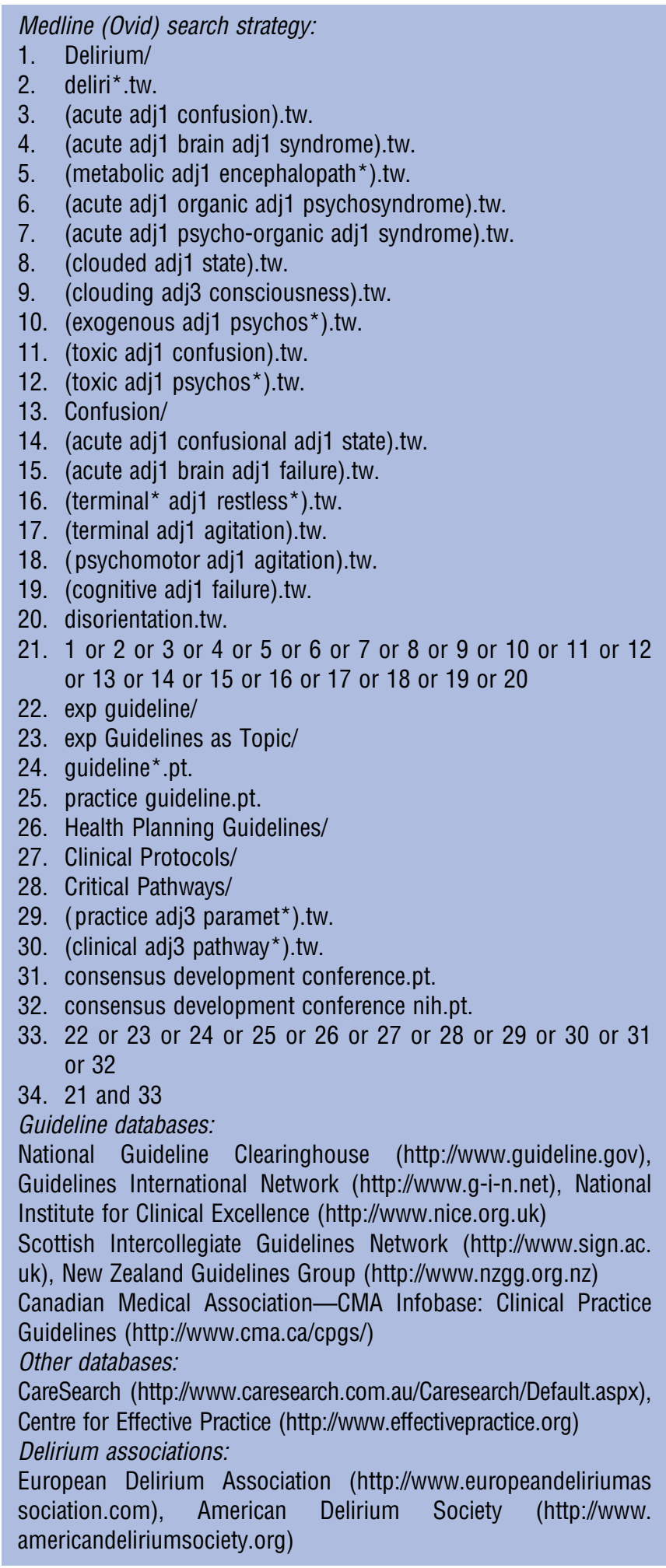

was used to appraise the quality of guidelines after all appraisers had completed standardised online training. ${ }^{33}$

\section{Delirium clinical practice guideline selection}

The retrieved citations and internet sources were initially independently screened by two appraisers (SB, KM) according to title and abstract. Inclusion criteria included: full and short versions of formal clinical practice guidelines, as defined by Field and Lohr (see above), ${ }^{26}$ with a focus on the topic of delirium and in any clinical setting for adults $\geq 18$ years, guideline summary papers and studies evaluating guidelines. Citations were excluded if the scope of the paper was on alcohol withdrawal delirium (delirium tremens), paediatric population only or literature reviews on delirium management (systematic or otherwise). Duplicates were included at this stage to identify individual citation numbers per database.

Citations meeting the above inclusion criteria went through a second-level screening of full-text articles and internet sources $(\mathrm{SB}, \mathrm{KM})$ to determine the delirium clinical practice guidelines to be assessed, with incongruities regarding a citation's eligibility being resolved by consensus. Guidelines to be assessed were defined as formal delirium guidelines, or clinical practice guidelines, with a focus on delirium assessment and/or management in an adult population ( $\geq 18$ years) in either English or French language, 'produced by a sanctioned legitimate group' (ie, a formal endorsed guideline development committee or task force, as opposed to an individual contributor) with a systematic literature search and including clear evidence-informed recommendations linked to defined levels of evidence, ${ }^{34}$ and published within one of the following three time periods: 2008-2013, 2003-2007, older than 2003. Guidelines that solely focused on the management of postoperative delirium were excluded as the authors' aim was to review guidelines that were most applicable to patients in a medical inpatient or palliative care setting. Delirium guidelines published between the years 2008 and 2013 were determined to be 'high priority' guidelines due to currency, thereby matching the NGC inclusion criteria that require its included guidelines to have been 'developed, reviewed or revised within the previous five years'. 35

Two appraisers (SB, KM) independently assessed delirium guidelines published between 2008 and 2013 using the 'Rigour' domain of the AGREE II instrument, as recommended by CAN-IMPLEMENT V.3.1. ${ }^{34} 37$ Differences were resolved by consensus. To include a local provincial delirium guideline, guidelines meeting an AGREE II 'Rigour of Development' domain cut-off of $>40 \%$ were submitted to the next step in quality assessment.

\section{Quality assessment of delirium guidelines}

Four members of the research team (SB/KM/MA/DD) independently appraised the final included guidelines using the full 23-item AGREE II instrument, followed by a teleconference consensus discussion among all four appraisers. Standardised domain scores for each of the six AGREE II domains were calculated as recommended by AGREE II. In addition, the appraisers added contemporaneous field notes and completed the two global 
rating items at the end of each AGREE II assessment. The first global rating item asks appraisers to rate the overall quality of the guideline on a 7-point scale (1= lowest possible quality and $7=$ highest possible quality). The second global rating item asks whether the appraiser would recommend the guideline for use in practice, with options of 'yes', 'yes, with modifications', and 'no'.

\section{RESULTS}

Systematic search for delirium clinical practice guidelines

The systematic search generated 3327 citations, of which 1629 were for the search strategy time period 20082013. Ninety-three database citations related to guidelines met the inclusion criteria (see figure 1). Second-level screening of full-text articles assessed some articles with the word 'guideline' in the title as literature reviews or protocols for delirium management without clear links between level of evidence and recommendations; these were excluded. The grey literature search of websites resulted in 21 additional documents related to 'guidelines'. The search of the global G-I-N Library using the term 'delirium' found 77 results out of 6444 entries. Seven entries appeared to meet the inclusion criteria of which only one had been retrieved from the above search. ${ }^{38}$ It was not possible to retrieve the other six possible guidelines (all non-English: four written in Dutch, one in French and one in German) as no research team member had G-I-N membership. ${ }^{39-44}$ With the addition of four delirium guidelines found on hand searching, a total of 118 retrieved guidelines and documents related to guidelines underwent full-text screening for eligibility.

Twenty-one stand-alone delirium guidelines were identified from the second-level screening; 11 published between 2008 and 2013, 7 between 2003 and 2007, and 3 guidelines published before 2003 (see tables 1 and 2).

The initial 'Rigour of Development' domain scores for the 11 guidelines $\leq 5$ years old from the two appraisers

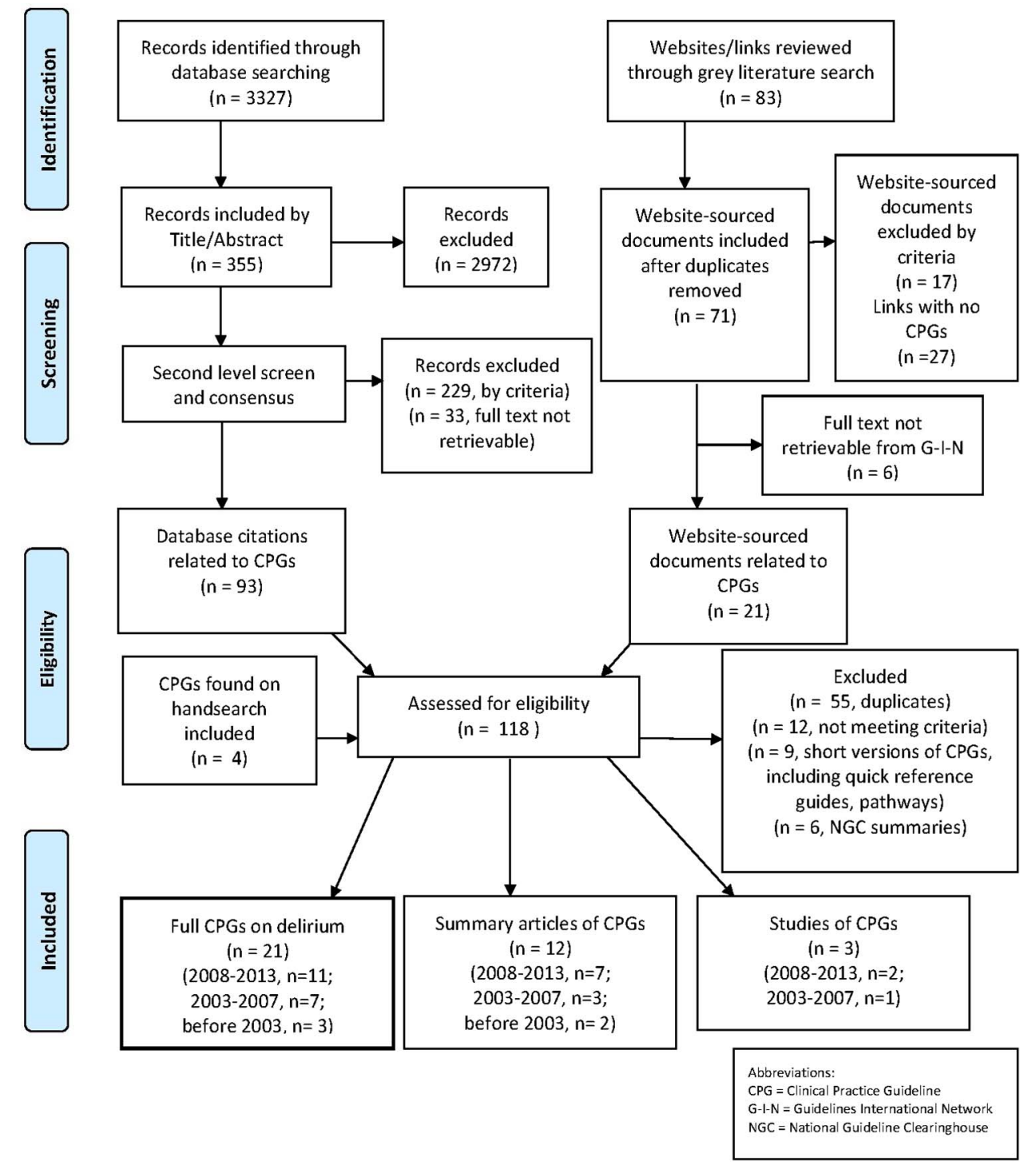

Figure 1 Flow diagram of delirium guideline selection procedure. 
ranged from $3 \%$ to $91 \%$ (see table 1 ). To include a local provincial delirium guideline, ${ }^{49}$ a 'Rigour' domain cut-off score of $>40 \%$ was used, resulting in a final seven 'high priority' guidelines requiring further evaluation, and four excluded guidelines. ${ }^{51-54}$

The final seven 'high priority' guidelines from 2008 to 2013 were all written in English, with four having been developed in Canada, two in the USA and one in the UK. Both guidelines from the Registered Nurses Association of Ontario (RNAO) were originally published in 2003: we evaluated the revised 2010 supplements. The 2009 full version of the guideline by Sendelbach et al (updated from 1998) was purchased from the University of Iowa after sourcing it via a website link on the Medline-retrieved summary guideline paper. The target users were healthcare providers for three guidelines, ${ }^{38} 4750$ healthcare providers providing care to patients with cancer-related symptom management throughout the disease trajectory for one guideline, ${ }^{49}$ nurses (Registered Nurses and Registered Practical Nurses) for two guidelines ${ }^{46}{ }^{48}$ and intensive care unit (ICU) clinicians for one guideline. ${ }^{45}$ Four guidelines were limited to older adults, ${ }^{46-48}{ }^{50}$ although only two provided an age definition for 'older adult'. The 2010 Clinical Guideline 103 (CG103) on delirium (with an 'Evidence Update' in April 2012 which was also reviewed by the appraisers) from the National Clinical Guideline Centre (NCGC) was commissioned by the National Institute for Health and Clinical Excellence (NICE). ${ }^{38}$ It was the longest guideline, comprising 447 pages in its full version in addition to 10 appendices, implementation tools and care pathway.

The NICE guideline specifically excluded 'people receiving end-of-life care'. The guideline by the Canadian Coalition for Seniors' Mental Health (CCSMH) was developed specifically for palliative care patients and defined 'approaching the end of life' as 'to living currently with a terminal illness and having an estimated life expectancy of six months or less'. ${ }^{47}$ The ICU guideline (for the management of pain, agitation and delirium or 'PAD') was published by Barr et $a l^{45}$ as a special article in a specialist journal, rather than as a stand-alone guideline. This meant that while it was easily sourced on searching electronic databases, such as Medline, CINAHL and EMBASE, the initial version of the guideline had to be cut by $10-20 \%$ due to journal space restrictions. ${ }^{65}$ Three guidelines searched for pre-existing guidelines from which to make their recommendations, as opposed to being de novo guidelines. ${ }^{4648} 49$

\section{Quality appraisal of selected guidelines (published} between 2008 and 2013) using the AGREE II instrument

Table 3 summarises the AGREE II domain scores and overall results of the quality assessment.

The seven selected 'high priority' delirium guidelines scored highest for the 'Scope and Purpose' domain (mean $80.1 \%$, range $64-100 \%$ ); and the 'Clarity and Presentation' domain (mean $76.7 \%$, range 38-97\%). Overall the lowest rating domains were Domain 5, 'Applicability' (mean 48.7\%, range $8-81 \%$ ), and Domain 6, 'Editorial Independence', (mean 53\%, range $2-90 \%)$. The mean values for the remaining two domains were $62.3 \%$ ('Rigour of Development') and $58.6 \%$ ('Stakeholder Involvement'). The 2010 NCGC/ NICE guideline was the highest rated guideline in five of the six domains (range 81-100\%). Only the 'PAD' ICU guideline, which was rated the highest for 'Editorial Independence', was recommended for use without modifications by all four appraisers.

The RNAO guidelines received the highest ratings for monitoring criteria (presented in the original 2003 and 2004 guidelines) and provided a link for a separate comprehensive Toolkit (available in English and French) for implementing guidelines ${ }^{66}$ The RNAO screening guideline had been pilot tested at three teaching hospitals, resulting in a summary of implementation strategies within the guideline. The NICE guideline had a costing report and costing template available, in addition to a brief implementation advice document and audit template. From the contemporaneous field notes, it was noted that the 'PAD' ICU guideline did not rely on expert opinion and explicitly made no recommendation if insufficient evidence or no group consensus reached. Two appraisers thought that the length of the full NICE guideline may impede implementation, but noted that the guideline had excellent summary documents including a 29-page shorter version and a 10-page 'Quick reference guide'. One appraiser found it challenging to navigate through PDF versions of several guidelines without running titles to define sections.

\section{Systematic search for guideline summaries, dissemination papers and studies}

For the years 2008-2013, four of the final seven appraised guidelines had published dissemination papers, with the NICE guideline having two summary publications ${ }^{17}{ }^{67}$ (see table 4). All the dissemination papers were sourced through Medline.

Three dissemination papers were published in 2003$2007,^{73-75}$ and two before $2003 .^{76}$ Six of the 11 retrieved guidelines (2008-2013) had guideline summaries published on the NGC website ${ }^{35}$ (see table 5).

From the literature search, only three studies (all cited in EMBASE) described the evaluation of implemented delirium guidelines. Mudge et $a l^{78}$ reported an Australian controlled trial of implementation of a 2006 guideline on the management of delirium in older people on a medical ward compared with a control ward. ${ }^{56}$ Twenty-two per cent of the patients were delirious on admission and no incident cases of delirium were identified. In the delirious subgroup, there was a trend to a lower use of antipsychotic medications $(26 \%$ vs $41 \%, \mathrm{p}=0.46)$. In the intervention group there was a longer duration of admission, a trend to reduced 
Table 1 AGREE II initial 'rigour' domain scores for delirium clinical practice guidelines (published 2008-2013)

\begin{tabular}{|c|c|c|c|c|c|c|}
\hline Clinical practice guideline name & $\begin{array}{l}\text { Guideline development } \\
\text { group }\end{array}$ & $\begin{array}{l}\text { Year of } \\
\text { publication }\end{array}$ & $\begin{array}{l}\text { Country/ } \\
\text { language }\end{array}$ & Database source & $\begin{array}{l}\text { Target patient } \\
\text { population }\end{array}$ & $\begin{array}{l}\text { Initial Rigour } \\
\text { domain } \\
\text { score }\end{array}$ \\
\hline $\begin{array}{l}\text { Delirium: diagnosis, prevention } \\
\text { and management. Clinical Guideline } \\
103(\mathrm{CG} 103)^{38}\end{array}$ & $\begin{array}{l}\text { National Clinical Guideline } \\
\text { Centre (NCGC): } \\
\text { Commissioned by National } \\
\text { Institute for Health and Care } \\
\text { Excellence (NICE) }\end{array}$ & 2010 & England: English & $\begin{array}{l}\text { Grey literature, } \\
\text { TRIP; Guideline } \\
\text { summary (NGC): } \\
\text { TRIP }\end{array}$ & $\begin{array}{l}\text { Adult patients } \geq 18 \text { years } \\
\text { in a hospital setting and } \\
\text { long-term residential care }\end{array}$ & $91 \%$ \\
\hline $\begin{array}{l}\text { Clinical practice guidelines for the } \\
\text { management of pain, agitation and } \\
\text { delirium in adult patients in the } \\
\text { intensive care unit }^{45}\end{array}$ & $\begin{array}{l}\text { The American College of } \\
\text { Critical Care Medicine task } \\
\text { force }\end{array}$ & 2013 & USA: English & $\begin{array}{l}\text { Medline, } \\
\text { EMBASE, } \\
\text { CINAHL; } \\
\text { Guideline } \\
\text { summary (NGC): } \\
\text { TRIP }\end{array}$ & $\begin{array}{l}\text { Intubated and } \\
\text { non-intubated adult } \\
\text { medical, surgical and } \\
\text { trauma intensive care } \\
\text { unit patients }\end{array}$ & $58 \%$ \\
\hline $\begin{array}{l}\text { Caregiving strategies for older adults } \\
\text { with delirium, dementia and } \\
\text { depression }^{46}\end{array}$ & $\begin{array}{l}\text { Registered Nurses Association } \\
\text { of Ontario (RNAO) }\end{array}$ & $\begin{array}{l}2010 \text { update } \\
\text { (Original: } \\
\text { 2004) }\end{array}$ & Canada: English & $\begin{array}{l}\text { Grey literature, } \\
\text { TRIP; Guideline } \\
\text { summary (NGC): } \\
\text { TRIP }\end{array}$ & $\begin{array}{l}\text { Older adults } \geq 65 \text { years } \\
\text { with delirium, dementia } \\
\text { and/or depression }\end{array}$ & $55 \%$ \\
\hline $\begin{array}{l}\text { Guideline on the assessment and } \\
\text { treatment of delirium in older adults at } \\
\text { the end of life }\end{array}$ & $\begin{array}{l}\text { Canadian Coalition for } \\
\text { Seniors' Mental Health } \\
\text { (CCSMH) }\end{array}$ & 2010 & Canada: English & Grey literature & $\begin{array}{l}\text { Older adults } \geq 65 \text { years } \\
\text { with or at risk of } \\
\text { developing delirium and } \\
\text { approaching the end of } \\
\text { life }\end{array}$ & $54 \%$ \\
\hline $\begin{array}{l}\text { Screening for delirium, dementia and } \\
\text { depression in older adults }{ }^{48}\end{array}$ & $\begin{array}{l}\text { Registered Nurses Association } \\
\text { of Ontario (RNAO) }\end{array}$ & $\begin{array}{l}2010 \text { update } \\
\text { (Original: } \\
\text { 2003) }\end{array}$ & Canada: English & $\begin{array}{l}\text { Grey literature, } \\
\text { TRIP; Guideline } \\
\text { summary (NGC): } \\
\text { TRIP }\end{array}$ & Older adult clients & $48 \%$ \\
\hline $\begin{array}{l}\text { Cancer Care Ontario's Symptom } \\
\text { management guide-to-practice: } \\
\text { Delirium }^{49}\end{array}$ & Cancer Care Ontario (CCO) & 2010 & Canada: English & Grey literature & $\begin{array}{l}\text { Adult patients who } \\
\text { require symptom } \\
\text { management related to } \\
\text { cancer }\end{array}$ & $43 \%$ \\
\hline Acute Confusion/Delirium ${ }^{50}$ & $\begin{array}{l}\text { Sendelbach S, Finch Guthrie } \\
\text { P. (University of lowa College } \\
\text { of Nursing) }\end{array}$ & 2009 & USA: English & $\begin{array}{l}\text { Hand search; } \\
\text { Guideline } \\
\text { summary (NGC): } \\
\text { TRIP }\end{array}$ & $\begin{array}{l}\text { Elderly hospitalised } \\
\text { patients (general } \\
\text { medical/surgical units) }\end{array}$ & $42 \%$ \\
\hline $\begin{array}{l}\text { Evidence and consensus-based } \\
\text { German guidelines for the } \\
\text { management of analgesia, sedation } \\
\text { and delirium in intensive care }{ }^{51}\end{array}$ & $\begin{array}{l}\text { Association of Scientific } \\
\text { Medical Societies (AWMF) of } \\
\text { Germany }\end{array}$ & 2010 & $\begin{array}{l}\text { Germany: } \\
\text { English (Original } \\
\text { version)/German }\end{array}$ & Medline & Critically ill patients & $21 \%$ \\
\hline
\end{tabular}




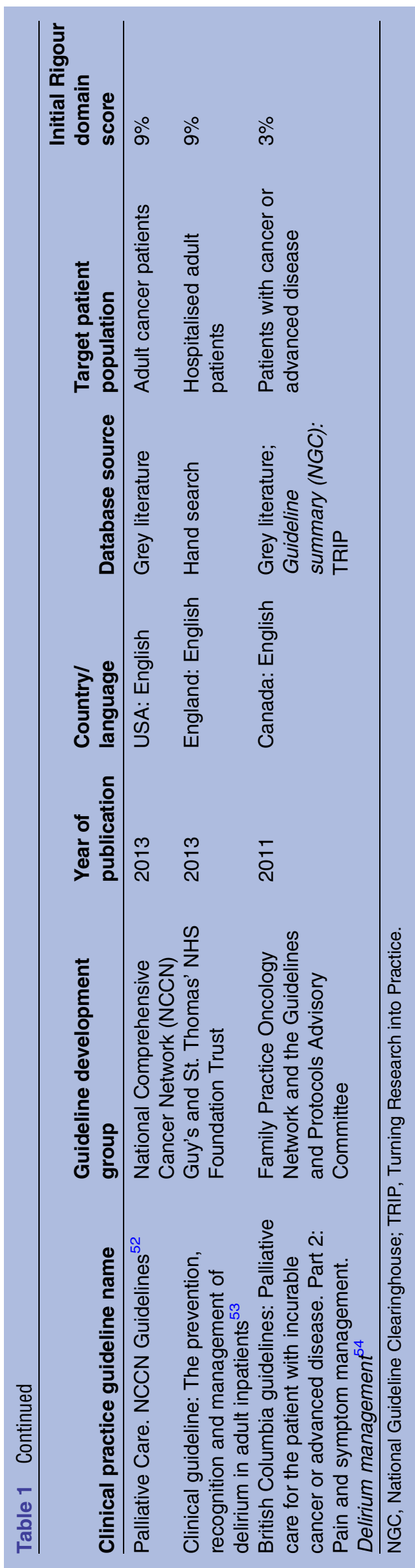

inpatient mortality, and significantly fewer patients were discharged with persistent delirium $(32 \%$ vs $71 \%$, $\mathrm{p}=0.016$ ). The authors commented that implementation was costly, aside from the cost due to increased length of acute ward stay. Voellinger $e t a l^{79}$ described the effect of guideline implementation in a general hospital in Switzerland on nurses' and physicians' knowledge after a 1-hour education session using pre-MCQ and post-MCQ questionnaires. The study illustrated the effort required for implementation but no assessment was made of clinical outcomes. In 2003, Young and George reported a pre-evaluation and postevaluation of the implementation using cluster randomisation of a British Geriatrics Society delirium guideline implemented in five hospitals with graduated 'intensity'. ${ }^{80}$ One hospital received the 'low-intensity' intervention: this consisted of feedback of baseline data alone from an earlier study. From chart review of patients with a diagnosis of delirium, the baseline data included frequency of mental test score administration, alcohol history, use of non-pharmacological management strategies and sedation, in addition to complications and length of stay. Two hospitals received the addition of guideline distribution to nurses and doctors ('medium-intensity' intervention); two hospitals received additional teaching sessions ('high-intensity' intervention). There was an improvement in process and outcome of care in the high-intervention group only, but this was not statistically significant. The authors concluded that guidelines themselves did not improve delirium management.

\section{DISCUSSION}

This study describes the systematic search process and quality appraisal of published delirium clinical guidelines across clinical settings. The key findings from the literature search were the importance of the grey literature search strategy to source delirium guidelines, as opposed to sourcing guideline summary papers and evaluation studies in indexed databases, and the lack of currency for many guidelines. Of note, nine of the 11 guidelines published between 2008 and 2013 were found solely through the grey literature search. This is in keeping with our previous experience of sourcing delirium guidelines, where a lower proportion of guidelines were retrieved from biomedical electronic databases. ${ }^{32}$ Similarly in a search for dementia guidelines, Azermai et $a l^{81}$ retrieved over half of the appraised guidelines from the web. For our study, the NGC website was an effective way to identify and source recently published guidelines. ${ }^{35} 82$ Only the CCSMH guideline for older adults with delirium at the end of life did not have an NGC guideline summary. ${ }^{47}$ However, the six delirium guidelines with NGC summaries varied with their final AGREE II 'Rigour of Development' domain ratings, with two rating below $40 \%$ in this domain. ${ }^{50}{ }^{54}$ In contrast to sourcing delirium guidelines, bibliographic databases appear to be the best source for guideline summary 
Table 2 Summary of delirium clinical practice guidelines published (1) between 2003 and 2007 (2) before 2003

\begin{tabular}{|c|c|c|c|c|c|c|}
\hline Delirium guideline name & Guideline development Group & Year & Country & Language & $\begin{array}{l}\text { Database } \\
\text { source }\end{array}$ & Target patient population \\
\hline $\begin{array}{l}\text { Delirium: Guidelines for general } \\
\text { hospitals }\end{array}$ & $\begin{array}{l}\text { The Delirium Guidelines } \\
\text { Development Group } \\
\text { 'A multidisciplinary expert panel' }\end{array}$ & 2007 & Switzerland & English & $\begin{array}{l}\text { Medline, } \\
\text { EMBASE, } \\
\text { PsycINFO }\end{array}$ & Adult patients in general hospitals \\
\hline $\begin{array}{l}\text { Clinical practice guidelines for the } \\
\text { management of delirium in older } \\
\text { people }\end{array}$ & $\begin{array}{l}\text { Clinical Epidemiology and Health } \\
\text { Service Evaluation Unit, Melbourne } \\
\text { Health in collaboration with the } \\
\text { Delirium Clinical Guidelines Expert } \\
\text { Working Group }\end{array}$ & 2006 & Australia & English & Grey literature & $\begin{array}{l}\text { Older people receiving care (in hospital, } \\
\text { community and residential care } \\
\text { settings) aged } \geq 65 \text { years, or } \geq 45 \text { years } \\
\text { in the case of Aboriginal and Torres } \\
\text { Strait Islander people }\end{array}$ \\
\hline $\begin{array}{l}\text { National guidelines for seniors' } \\
\text { mental health: The assessment } \\
\text { and treatment of delirium }{ }^{57}\end{array}$ & $\begin{array}{l}\text { Canadian Coalition for Seniors' } \\
\text { Mental Health (CCSMH) }\end{array}$ & 2006 & Canada & $\begin{array}{l}\text { English/ } \\
\text { French }\end{array}$ & Grey literature & $\begin{array}{l}\text { Older adults } \geq 65 \text { years, all healthcare } \\
\text { settings }\end{array}$ \\
\hline $\begin{array}{l}\text { Symptom Guidelines: Delirium/ } \\
\text { Restlessness }^{58}\end{array}$ & $\begin{array}{l}\text { Hospice Palliative Care Clinical } \\
\text { Practice Guideline Committee, Fraser } \\
\text { Health }\end{array}$ & 2006 & Canada & English & Grey literature & $\begin{array}{l}\text { Adult patients } \geq 19 \text { years living with } \\
\text { advanced life-threatening illness }\end{array}$ \\
\hline $\begin{array}{l}\text { Guidelines for the prevention, } \\
\text { diagnosis and management of } \\
\text { delirium in older people. Concise } \\
\text { guidance to good practice series, } \\
\text { No } 6^{59}\end{array}$ & $\begin{array}{l}\text { Guideline Development Group: British } \\
\text { Geriatrics Society and Royal College } \\
\text { of Physicians }\end{array}$ & 2006 & UK & English & Hand search & $\begin{array}{l}\text { Older people in hospital and community } \\
\text { care settings }\end{array}$ \\
\hline $\begin{array}{l}\text { Detection, prevention and } \\
\text { treatment of delirium in critically ill } \\
\text { patients }\end{array}$ & UK Clinical Pharmacy Association & 2006 & UK & English & Hand search & Critically ill patients \\
\hline (Guideline: Delirium) $^{61}$ & $\begin{array}{l}\text { Dutch Psychiatric Association. van } \\
\text { der Mast RC et al }\end{array}$ & 2005 & Netherlands & Dutch & $\begin{array}{l}\text { Medline, } \\
\text { EMBASE }\end{array}$ & Not known due to language restriction \\
\hline $\begin{array}{l}\text { Clinical practice guidelines for the } \\
\text { sustained use of sedatives and } \\
\text { analgesics in the critically ill } \\
\text { adult }^{62}\end{array}$ & $\begin{array}{l}\text { Sedation and Analgesia Taskforce, } \\
\text { Society of Critical Care Medicine and } \\
\text { American Society of Health-System } \\
\text { Pharmacists }\end{array}$ & 2002 & USA & English & EMBASE & Critically ill adults \\
\hline $\begin{array}{l}\text { Clinical practice guideline: } \\
\text { Delirium in the elderly }{ }^{63}\end{array}$ & Fraser Health Authority & 2002 & Canada & English & Grey literature & Elderly patients with delirium \\
\hline $\begin{array}{l}\text { Practice guideline for the } \\
\text { treatment of patients with } \\
\text { delirium }^{64}\end{array}$ & American Psychiatric Association & 1999 & USA & English & $\begin{array}{l}\text { Medline, } \\
\text { EMBASE, } \\
\text { PsycINFO, Grey } \\
\text { literature } \\
\end{array}$ & Patients with delirium \\
\hline
\end{tabular}


Table 3 Final AGREE II domain scores and global ratings

\begin{tabular}{|c|c|c|c|c|c|c|c|c|}
\hline Delirium guideline name & $\begin{array}{l}\text { Domain 1: } \\
\text { Scope and } \\
\text { Purpose }\end{array}$ & $\begin{array}{l}\text { Domain 2: } \\
\text { Stakeholder } \\
\text { Involvement }\end{array}$ & $\begin{array}{l}\text { Domain 3: } \\
\text { Rigour of } \\
\text { Development }\end{array}$ & $\begin{array}{l}\text { Domain 4: } \\
\text { Clarity of } \\
\text { Presentation }\end{array}$ & $\begin{array}{l}\text { Domain 5: } \\
\text { Applicability }\end{array}$ & $\begin{array}{l}\text { Domain 6: } \\
\text { Editorial } \\
\text { Independence }\end{array}$ & $\begin{array}{l}\text { Overall } \\
\text { global rating } \\
\text { scale } \\
\text { (average) }\end{array}$ & $\begin{array}{l}\text { Overall } \\
\text { recommendation } \\
\text { (to use guideline) }\end{array}$ \\
\hline $\begin{array}{l}\text { Delirium: diagnosis, prevention } \\
\text { and management (NICE Clinical } \\
\text { Guideline } 103 \text { (CG103)) })^{38}\end{array}$ & $100 \%$ & $85 \%$ & $93 \%$ & $97 \%$ & $81 \%$ & $85 \%$ & 6.75 & $\begin{array}{l}\text { Yes }(3 \text { reviewers) } \\
\text { Yes with modifications } \\
\text { (1 reviewer) }\end{array}$ \\
\hline $\begin{array}{l}\text { Clinical practice guidelines for the } \\
\text { management of pain, agitation } \\
\text { and delirium in adult patients in } \\
\text { the intensive care unit }{ }^{45}\end{array}$ & $96 \%$ & $56 \%$ & $78 \%$ & $93 \%$ & $60 \%$ & $90 \%$ & 6.25 & Yes (4 reviewers) \\
\hline $\begin{array}{l}\text { Caregiving strategies for older } \\
\text { adults with delirium, dementia and } \\
\text { depression }^{46}\end{array}$ & $86 \%$ & $58 \%$ & $65 \%$ & $85 \%$ & $69 \%$ & $46 \%$ & 6.75 & $\begin{array}{l}\text { Yes ( } 2 \text { reviewers) } \\
\text { Yes with modifications } \\
\text { (2 reviewers) }\end{array}$ \\
\hline $\begin{array}{l}\text { Guideline on the assessment and } \\
\text { treatment of delirium in older } \\
\text { adults at the end of life }{ }^{47}\end{array}$ & $76 \%$ & $65 \%$ & $58 \%$ & $74 \%$ & $8 \%$ & $44 \%$ & 4.5 & $\begin{array}{l}\text { Yes ( } 1 \text { reviewer) } \\
\text { Yes with modifications } \\
\text { (3 reviewers) }\end{array}$ \\
\hline $\begin{array}{l}\text { Screening for delirium, dementia } \\
\text { and depression in older adults }{ }^{48}\end{array}$ & $71 \%$ & $60 \%$ & $61 \%$ & $79 \%$ & $72 \%$ & $48 \%$ & 5 & $\begin{array}{l}\text { Yes ( } 3 \text { reviewers) } \\
\text { Yes with modifications } \\
\text { (1 reviewer) }\end{array}$ \\
\hline $\begin{array}{l}\text { Cancer Care Ontario's Symptom } \\
\text { management guide-to-practice: } \\
\text { Delirium }^{49}\end{array}$ & $68 \%$ & $58 \%$ & $47 \%$ & $71 \%$ & $16 \%$ & $56 \%$ & 3.75 & $\begin{array}{l}\text { Yes ( } 1 \text { reviewer) } \\
\text { Yes with modifications } \\
\text { (3 reviewers) }\end{array}$ \\
\hline Acute Confusion/Delirium ${ }^{50}$ & $64 \%$ & $28 \%$ & $34 \%$ & $38 \%$ & $35 \%$ & $2 \%$ & 3.5 & $\begin{array}{l}\text { No ( } 2 \text { reviewers) } \\
\text { Yes with modifications } \\
\text { (2 reviewers) }\end{array}$ \\
\hline Mean & $80.1 \%$ & $58.6 \%$ & $62.3 \%$ & $76.7 \%$ & $48.7 \%$ & $53.0 \%$ & & \\
\hline Range & $64-100 \%$ & $28-85 \%$ & $34-93 \%$ & $38-97 \%$ & $8-81 \%$ & $2-90 \%$ & & \\
\hline
\end{tabular}


Table 4 Retrieved dissemination summary papers for delirium guidelines (2008-2013)

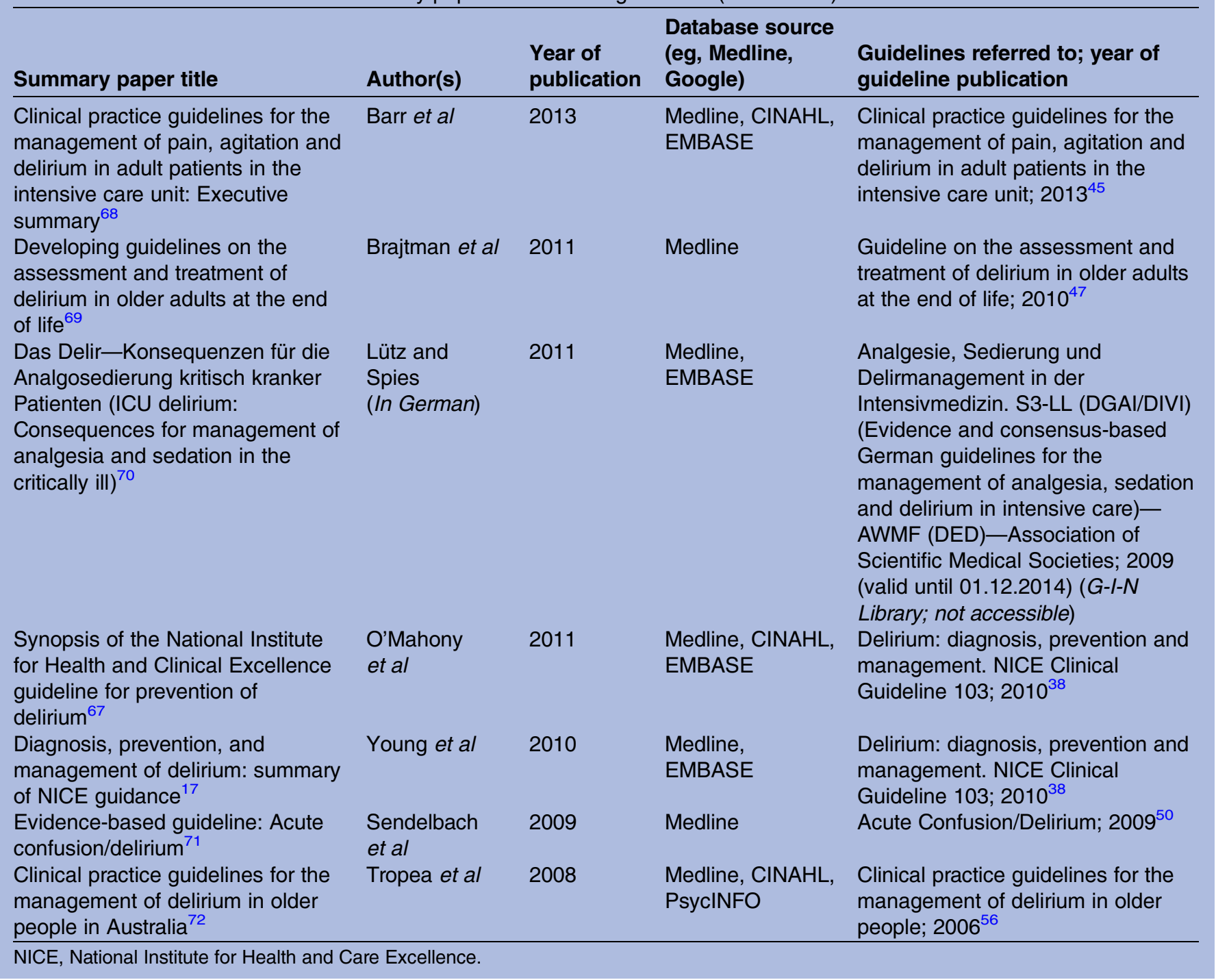

papers as part of a guideline dissemination strategy. In this study, all the summary papers of delirium guidelines published between 2008 and 2013 were cited in the Medline database, as well as some of the other commonly used electronic databases. It was disappointing to find little evidence for further knowledge translation with only three publications from 2003 to 2013 describing the formal evaluation of fully implemented delirium guidelines (as opposed to published reports of the implementation process and facilitators and barriers to guideline implementation) being retrieved. Almost $50 \%$ of the delirium guidelines were $>5$ years old, yet the median lifespan of NICE guidelines is 60 months. ${ }^{83}$ It is important for guidelines to maintain currency and remain relevant and valid with mechanisms designed to incorporate important new research findings efficiently. A 'red flag monitoring system' has been proposed to allow timely incorporation of exceptional updates with the collation of alerts and medical product safety information from national authorities, for example, US Food and Drug Administration (FDA), Health
Canada, European Medicines Agency. ${ }^{84}$ Partial updating of guidelines from systematic monitoring may be more practical, cost-effective and provide more timely recommendations than using scheduled full updates (usually every $3-5$ years).

A key finding of the quality appraisal was the variation in quality of formal delirium clinical guidelines across all six AGREE II domains and lack of practical implementation and audit tools for many guidelines. Performing an initial AGREE II assessment with two appraisers evaluating the 'Rigour' dimension was a practical way to reduce the number of delirium guidelines requiring full AGREE II appraisal. The 2010 NICE delirium guideline received the highest AGREE II overall quality rating and domain scores for all domains, except 'Editorial Independence'. ${ }^{38}$ Considering all seven delirium guidelines (published between 2008 and 2013) selected for the full AGREE II appraisal, the 'Applicability' and 'Editorial Independence' domains were frequently the lowest rated. This result is similar to findings by other authors appraising guidelines with the original AGREE 
Table 5 National Guideline Clearinghouse (NGC) published summaries for delirium guidelines (2008-2013)

\begin{tabular}{|c|c|c|c|c|}
\hline $\begin{array}{l}\text { NGC guideline } \\
\text { summary name }\end{array}$ & Guideline developer & Year & $\begin{array}{l}\text { Delirium clinical practice guidelines } \\
\text { referred to }\end{array}$ & Country \\
\hline $\begin{array}{l}\text { Guideline } \\
\text { summary } \\
\text { NGC-9692 }\end{array}$ & $\begin{array}{l}\text { Society of Critical Care } \\
\text { Medicine }\end{array}$ & $\begin{array}{l}2013 \text { (revision of } \\
1995 \text { version) }\end{array}$ & $\begin{array}{l}\text { Clinical practice guidelines for the } \\
\text { management of pain, agitation and delirium } \\
\text { in adult patients in the intensive care unit }{ }^{45}\end{array}$ & USA \\
\hline $\begin{array}{l}\text { Guideline } \\
\text { summary } \\
\text { NGC-9461 }\end{array}$ & $\begin{array}{l}\text { Family Practice Oncology } \\
\text { Network; Medical Services } \\
\text { Commission }\end{array}$ & 2011 & $\begin{array}{l}\text { British Columbia guidelines: Palliative care } \\
\text { for the patient with incurable cancer or } \\
\text { advanced disease. Part 2: Pain and } \\
\text { symptom management }{ }^{54}\end{array}$ & Canada \\
\hline $\begin{array}{l}\text { Guideline } \\
\text { summary } \\
\text { NGC-8072 }\end{array}$ & $\begin{array}{l}\text { National Clinical Guideline } \\
\text { Centre for Acute and } \\
\text { Chronic Conditions }\end{array}$ & 2010 & $\begin{array}{l}\text { Delirium: diagnosis, prevention and } \\
\text { management. NICE Clinical Guideline } 103^{38}\end{array}$ & UK \\
\hline $\begin{array}{l}\text { Guideline } \\
\text { summary } \\
\text { NGC-8381 }\end{array}$ & $\begin{array}{l}\text { Registered Nurses' } \\
\text { Association of Ontario }\end{array}$ & $\begin{array}{l}2004 \text { (addendum } \\
\text { released May } \\
\text { 2010) }\end{array}$ & $\begin{array}{l}\text { Caregiving strategies for older adults with } \\
\text { delirium, dementia and depression }{ }^{46}\end{array}$ & Canada \\
\hline $\begin{array}{l}\text { Guideline } \\
\text { summary } \\
\text { NGC-8380 }\end{array}$ & $\begin{array}{l}\text { Registered Nurses' } \\
\text { Association of Ontario }\end{array}$ & $\begin{array}{l}2003 \text { (addendum } \\
\text { released May } \\
\text { 2010) }\end{array}$ & $\begin{array}{l}\text { Screening for delirium, dementia and } \\
\text { depression in older adults }{ }^{48}\end{array}$ & Canada \\
\hline $\begin{array}{l}\text { Guideline } \\
\text { summary } \\
\text { NGC-7208 }\end{array}$ & $\begin{array}{l}\text { University of lowa College } \\
\text { of Nursing }\end{array}$ & $\begin{array}{l}2009 \text { (revision of } \\
1998 \text { version) }\end{array}$ & Acute Confusion/Delirium ${ }^{50}$ & USA \\
\hline
\end{tabular}

instrument or updated AGREE II version. ${ }^{81}{ }^{85-87}$ As the four items for the AGREE II 'Applicability' domain (facilitators and barriers to guideline application, provision of implementation tools and/or advice on how to put recommendations into practice, consideration of resource implications, and provision of monitoring and/ or audit criteria) help healthcare providers operationalise a guideline into clinical practice as well as monitor its effectiveness, a low-rating 'Applicability' domain may lead to challenges with sustainability of the guideline once implemented. As part of the AGREE II 'Editorial Independence' domain, it is vital that members of a guideline development committee have declared any potential conflicts of interest, especially financial, or links with industry, and that this information is clearly accessible within the guideline itself or as an appendix, to ensure that the reader is well informed and can assess for potential bias. ${ }^{29}$

A strength of this study is the usage of an experienced university health sciences librarian to assist with the development of the search strategy for the systematic literature search. Adding to the methodological rigour and reliability of the AGREE II assessment, a complement of four (rather than two) appraisers conducted the full AGREE II quality assessment of the delirium guidelines. This is in keeping with the recommendations of the AGREE II user's manual. ${ }^{33}$ Although the appraisers were inexperienced in guideline evaluation, all had completed the AGREE II online training module. All appraisers had clinical and research interests in delirium in palliative care or older populations. A limitation is that it was not possible to retrieve the full text for all the citations from the literature search or from the G-I-N
International Guideline Library, in addition to the language restriction to English and French for the second-level screening. While it is necessary to be a subscribed G-I-N member to retrieve guidelines from the G-I-N website, it is possible to search the International Guideline Library for identification of guidelines and whether the guideline status is 'in development', 'published' or 'under review'. ${ }^{36}$ For this study, the full AGREE appraisal focused on 'recent' delirium guidelines that had been published within the previous 5 years at the time of the literature search. The literature continues to evolve with the subsequent development or revision of guidelines, which were not included as part of this study. The CCSMH has published a 2014 update (in English and French) for its 2006 guideline on 'The assessment and treatment of delirium' in seniors. ${ }^{88}$ From the G-I-N website, ${ }^{36}$ the Dutch College of General Practitioners published Delier (M77) (Delirium) on 1 April 2014. This appears to be an update of a 2003 (M77) guideline. From the NICE website, the next review date for the NICE CG103 guideline is 2018, as there was found to be no requirement to update this guideline at the last review in January 2015. ${ }^{38}$

This study confirms the importance of systematic grey literature searches to source tangible delirium clinical practice guidelines, and to ensure important guidelines are not overlooked. Poor accessibility of a guideline reduces compliance, in addition to its complexity and length. ${ }^{89}$ This study also illustrates the importance of using a formal appraisal tool, such as a full AGREE II assessment, to ensure that only high-quality delirium guidelines are adapted by clinicians for use in practice. Strengthening of items derived from the AGREE II 
'Applicability' domain would improve many of the delirium guidelines that we reviewed. By providing a robust 'Applicability domain', guideline developers can assist busy healthcare providers at the bedside with specific audit recommendations and provision of user-friendly templates for comparative audits preguideline and postguideline implementation, in addition to practical implementation tools. We envision that by using the recently published AGREE Reporting Checklist (available on the AGREE Enterprise website as a free and open access resource (http://www.agreetrust.org)), guideline development groups will improve the comprehensiveness and completeness of new guidelines across all AGREE II domains. ${ }^{90}$ The AGREE II instrument was developed from the original AGREE version. ${ }^{91}{ }^{92}$ While to the authors' knowledge, the AGREE II has not been subsequently revalidated, AGREE II is widely accepted and has been used extensively to appraise guidelines. ${ }^{93}$ The AGREE II does not formally evaluate the content of a guideline, including guideline criteria for evidence or the validity of guideline recommendations. Indeed it has been shown that the methodological quality of guidelines should not infer content validity. ${ }^{94}$

We found limited evidence of evaluation studies of delirium guidelines (with or without local adaptation) in their implemented settings. In addition to assessing the impact of guidelines on the quality of care, other identified desired outcomes, and assessment of guideline sustainability and cost-effectiveness, there should also be assessments for unintended consequences or undesirable outcomes to ensure that patient health and family outcomes are improved. A limitation to this study in assessing impact of guidelines is that it only included scientific literature and guidelines that had been published or retrieved by the grey literature search. The extensive quality assessment and improvement initiatives that are in place in individual institutions and networks across the world and their impact on care were not examined. Considering that the development and implementation of formal guidelines can be challenging, taking time, money and resources at the local level, a possible practical starting point to improve care is to encourage uptake and benchmarking of quality improvement measures related to delirium. NICE quality standards are concise and measurable enabling the development of local quality measures. ${ }^{95}$ For example, the NICE Quality Standard 63 for delirium management recommends five key standards. ${ }^{96}$

Future research needs to ensure that clinical practice guidelines are of high quality, user-friendly, relevant and non-biased as only 'rigorous' guidelines should be adapted into formats suitable for use in daily clinical practice. Crucial outstanding factors to enable guidelines to change practice are effective interprofessional implementation strategies at the local level to optimise uptake, maximum accessibility of guideline key points with practical and simple interprofessional clinical prompts and algorithms available at the point of care, and ensuring ongoing sustainability with long-term organisational support. A challenge for delirium guidelines in general remains the need for more primary research evidence (and higher quality studies) to inform them.

Acknowledgements The authors would like to acknowledge the assistance of Dr Christopher Klinger in translating part of the German 'Das Delir' summary paper, and Dr lan Graham, Centre for Practice-Changing Research, The Ottawa Hospital Research Institute, for his support in developing this project.

Contributors SB conceived and designed the study, and drafted and revised the manuscript. She is the guarantor. LS developed the database literature search strategy. SB and KM performed the initial abstract and full-text screening. SB, KM, MA and DD appraised the guidelines with the full AGREE II instrument. TT conducted the grey literature search and coordinated the online AGREE appraisal system. SB led the collection, analysis and interpretation of the data. All researchers had access to the data. All authors made substantial contributions to the study concept and the interpretation of the data, critically revised the article for important intellectual content and approved the final version of the manuscript to be published. The guarantor (SB) affirms that the manuscript is an honest, accurate, and transparent account of the study being reported and that no important aspects of the study have been omitted.

Funding This study was supported in part by funding from a Bruyère Academic Medical Organization 2014 Incentive grant (SB), entitled 'The development, implementation and evaluation of a delirium clinical practice guideline on the palliative care unit'.

Disclaimer The funders played no role in the study design, collection, analysis, interpretation of data, writing of the report or in the decision to submit the article for publication.

Competing interests All authors have completed the ICMJE uniform disclosure at www.icmje.org/coi_disclosure.pdf and declare that SB has received a research grant from the Bruyère Academic Medical Organization, and a research award from the Department of Medicine, University of Ottawa; SB was an external reviewer for four sections of the Canadian Coalition for Seniors' Mental Health (CCSMH) guideline for older adults at the end of life.

Ethics approval Review by a Human Ethics Review Committee was not required as this research involved only review of published work and did not involve any data collection from humans.

Provenance and peer review Not commissioned; externally peer reviewed.

Data sharing statement No additional data are available.

Open Access This is an Open Access article distributed in accordance with the Creative Commons Attribution Non Commercial (CC BY-NC 4.0) license, which permits others to distribute, remix, adapt, build upon this work noncommercially, and license their derivative works on different terms, provided the original work is properly cited and the use is non-commercial. See: http:// creativecommons.org/licenses/by-nc/4.0/

\section{REFERENCES}

1. American Psychiatric Association. Diagnostic and Statistical Manual of Mental Disorders: DSM-5. Arlington, VA: American Psychiatric Association, 2013

2. Inouye SK, Westendorp RG, Saczynski JS. Delirium in elderly people. Lancet 2014;383:911-22.

3. Ryan DJ, O'Regan NA, Caoimh RÓ, et al. Delirium in an adult acute hospital population: predictors, prevalence and detection. BMJ Open 2013;3:pii: e001772.

4. Hosie A, Davidson PM, Agar M, et al. Delirium prevalence, incidence, and implications for screening in specialist palliative care inpatient settings: a systematic review. Palliat Med 2013;27:486-98.

5. Ouimet S, Kavanagh BP, Gottfried SB, et al. Incidence, risk factors and consequences of ICU delirium. Intensive Care Med 2007;33:66-73. 
6. McNicoll L, Pisani MA, Zhang Y, et al. Delirium in the intensive care unit: occurrence and clinical course in older patients. J Am Geriatr Soc 2003;51:591-8.

7. Lawlor PG, Gagnon B, Mancini IL, et al. Occurrence, causes, and outcome of delirium in patients with advanced cancer: a prospective study. Arch Intern Med 2000;160:786-94.

8. Collins N, Blanchard MR, Tookman A, et al. Detection of delirium in the acute hospital. Age Ageing 2010;39:131-5.

9. Barron EA, Holmes J. Delirium within the emergency care setting, occurrence and detection: a systematic review. Emerg Med $J$ 2013;30:263-8.

10. Hey J, Hosker C, Ward J, et al. Delirium in palliative care: detection, documentation and management in three settings. Palliat Support Care 2015;13:1541-5.

11. El Hussein M, Hirst S, Salyers V. Factors that contribute to underrecognition of delirium by registered nurses in acute care settings: a scoping review of the literature to explain this phenomenon. J Clin Nurs 2015;24:906-15.

12. Teodorczuk A, Reynish E, Milisen K. Improving recognition of delirium in clinical practice: a call for action. BMC Geriatr 2012;12:55.

13. Fong TG, Tulebaev SR, Inouye SK. Delirium in elderly adults: diagnosis, prevention and treatment. Nat Rev Neurol 2009;5:210-20.

14. Pendlebury ST, Lovett NG, Smith SC, et al. Observational, longitudinal study of delirium in consecutive unselected acute medical admissions: age-specific rates and associated factors, mortality and re- admission. BMJ Open 2015;5:e007808.

15. Davis $\mathrm{DH}$, Muniz Terrera $\mathrm{G}$, Keage $\mathrm{H}$, et al. Delirium is a strong risk factor for dementia in the oldest-old: a population-based cohort study. Brain 2012;135(Pt 9):2809-16.

16. Breitbart W, Gibson C, Tremblay A. The delirium experience: delirium recall and delirium-related distress in hospitalized patients with cancer, their spouses/caregivers, and their nurses. Psychosomatics 2002;43:183-94.

17. Young J, Murthy L, Westby M, et al., Guideline Development Group. Diagnosis, prevention, and management of delirium: summary of NICE guidance. BMJ 2010;341:c3704.

18. Lacasse $\mathrm{H}$, Perreault MM, Williamson DR. Systematic review of antipsychotics for the treatment of hospital-associated delirium in medically or surgically ill patients. Ann Pharmacother 2006;40:1966-73.

19. Bush SH, Kanji S, Pereira JL, et al. Treating an established episode of delirium in palliative care: expert opinion and review of the current evidence base with recommendations for future development. J Pain Symptom Manage 2014;48:231-48.

20. Candy B, Jackson KC, Jones L, et al. Drug therapy for delirium in terminally ill adult patients. Cochrane Database of Systematic Reviews 2012;11:CD004770.

21. Neufeld KJ, Yue J, Robinson TN, et al. Antipsychotic medication for prevention and treatment of delirium in hospitalized adults: a systematic review and meta-analysis. J Am Geriatr Soc 2016;64:705-14.

22. Inouye SK, Marcantonio ER, Metzger ED. Doing damage in delirium: the hazards of antipsychotic treatment in elderly persons. Lancet Psychiatry 2014;1:312-5

23. Maust DT, Kim HM, Seyfried LS, et al. Antipsychotics, other psychotropics, and the risk of death in patients with dementia: number needed to harm. JAMA Psychiatry 2015;72:438-45.

24. Serafim RB, Bozza FA, Soares M, et al. Pharmacologic prevention and treatment of delirium in intensive care patients: a systematic review. J Critic Care 2015;30:799-807.

25. Shaneyfelt T. In guidelines we cannot trust: comment on failure of clinical practice guidelines to meet institute of medicine standards. Arch Intern Med 2012;172:1633-4.

26. Field ML, Lohr KN. Clinical practice guidelines: Directions for a new program. Washington DC: National Academy Press, 1990.

27. Davis D, Goldman J, Palda VA. Handbook on Clinical Practice Guidelines. Toronto: Canadian Medical Association, 2007.

28. Lenzer J. Why we can't trust clinical guidelines. BMJ 2013;346: f3830.

29. Lenzer J, Hoffman JR, Furberg CD, et al. Ensuring the integrity of clinical practice guidelines: a tool for protecting patients. BMJ 2013;347:f5535.

30. Kung J, Miller RR, Mackowiak PA. Failure of clinical practice guidelines to meet institute of medicine standards: Two more decades of little, if any, progress. Arch Intern Med 2012;172:1628-33.

31. ADAPTE Collaboration. http://www.g-i-n.net/working-groups/ adaptation/history

32. Bush SH, Bruera E, Lawlor PG, et al. Clinical practice guidelines for delirium management: potential application in palliative care. $J$ Pain Symptom Manage 2014;48:249-58.
33. Brouwers MC, Kho ME, Browman GP, et al., on behalf of the AGREE Next Steps Consortium. AGREE II: advancing guideline development, reporting and evaluation in health care. Can Med Assoc J 2010;182:E839-42.

34. Harrison MB, van den Hoek J. for the Canadian Guideline Adaptation Study Group. CAN- IMPLEMENTC: a Guideline Adaptation and Implementation Planning Resource. Kingston, Ontario, Canada: Queen's University School of Nursing and Canadian Partnership Against Cancer, April 2012.

35. National Guideline Clearinghouse (NGC) (cited 9 March 2016). http://www.guideline.gov

36. Guidelines International Network (G-I-N) International Guideline Library (cited 9 March 2016). http://www.g-i-n.net/library/ international-guidelines-library

37. Graham ID, Harrison MB. Evaluation and adaptation of clinical practice guidelines. Evid Based Nurs 2005;8:68-72.

38. National Clinical Guideline Centre. Delirium: diagnosis, prevention and management. Clinical Guideline 103. London: National Clinica Guideline Centre (NCGC)-Acute and Chronic Conditions, 2010. http://www.nice.org.uk/CG103

39. Delirium (English version) [Delirium]-IKNL (NL) Comprehensive Cancer Centre, The Netherlands. 2010.

40. Delier. National consensus-based guideline [Delirium]. The Netherlands, 2010.

41. Delier bij ouderen (M77). [Delirium in the elderly]-NHG (NL). The Netherlands: Dutch College of General Practitioners., 2003.

42. Delirium-CBO (NL). Dutch Institute for Healthcare Improvement CBO. The Netherlands, 2010.

43. Confusion aiguë chez la personne âgée: prise en charge initiale de l'agitation. Recommandation pour la pratique clinique [Acute confusion in older people]-HAS (FR) French National Authority for Health (formerly: ANAES). France. 2009.

44. Analgesie, Sedierung und Delirmanagement in der Intensivmedizin. S3-LL (DGAI/DIVI) [Evidence and consensus-based German guidelines for the management of analgesia, sedation and delirium in intensive care]-AWMF (DED). Germany: Association of Scientific Medical Societies, 2009.

45. Barr J, Fraser GL, Puntillo K, et al. Clinical practice guidelines for the management of pain, agitation, and delirium in adult patients in the intensive care unit. Crit Care Med 2013;41:263-306.

46. Registered Nurses Association of Ontario. Caregiving Strategies for Older Adults with Delirium, Dementia and Depression. Revised 2010 Supplement. Toronto: Registered Nurses Association of Ontario, 2004.

47. Canadian Coalition for Seniors' Mental Health. Guideline on the assessment and treatment of delirium in older adults at the end of life. Toronto: Canadian Coalition for Seniors' Mental Health (CCSMH), 2010.

48. Registered Nurses Association of Ontario. Screening for Delirium, Dementia and Depression in Older Adults. Revised 2010 Supplement. Toronto: Registered Nurses Association of Ontario, 2003.

49. Cancer Care Ontario. Symptom Management Guide-to-Practice: Delirium. Ontario: Cancer Care Ontario (CCO), 2010.

50. Sendelbach S, Finch Guthrie P. The University of lowa College of Nursing. Acute Confusion/Delirium Evidence-based Guideline. lowa City: The John A. Hartford Foundation Center of Geriatric Nursing Excellence (HCGNE), 2009.

51. Martin J, Heymann A, Basell K, et al. Evidence and consensus-based German guidelines for the management of analgesia, sedation and delirium in intensive care--short version. German Medical Science 2010;8:Doc02.

52. National Comprehensive Cancer Network. NCCN Clinical Practice guidelines in Oncology: Palliative care, Version 2.2013. Delirium PAL-21. USA: National Comprehensive Cancer Network (NCCN), 2013.

53. Guy's and St Thomas NHS Foundation Trust. Clinical Guideline: The Prevention, Recognition and Management of Delirium in Adult In-Patients. London: Guy's and St Thomas NHS Foundation Trust, 2011.

54. Family Practice Oncology Network and the Guidelines and Protocols Advisory Committee. Palliative care for the patient with incurable cancer or advanced disease. Part 2: Pain and symptom management: Delirium management. Victoria: Guidelines and Protocols Advisory Committee, 2011.

55. Michaud L, Bula C, Berney A, et al. Delirium: guidelines for genera hospitals. J Psychosom Res 2007;62:371-83.

56. Clinical Epidemiology and Health Service Evaluation Unit. Clinical practice guidelines for the management of delirium in older people. Melbourne: Victorian Government Department of Human Services, 2006. 
57. Canadian Coalition for Seniors' Mental Health. National Guidelines for Seniors' Mental Health: the assessment and treatment of delirium. Toronto: Canadian Coalition for Seniors' Mental Health (CCSMH), 2006.

58. Hospice Palliative Care Program Symptom Guidelines. Delirium/ Restlessness. British Columbia: Fraser Health, 2006.

59. British Geriatrics Society and Royal College of Physicians. Guidelines for the prevention, diagnosis and management of delirium in older people. Concise guidance to good practice series, No 6. London: RCP, 2006.

60. United Kingdom Clinical Pharmacy Association. Detection, prevention and treatment of delirium in critically ill patients.UK: UKCPA, 2006.

61. van der Mast RC, Huyse FJ, Rosier PF. [Guideline 'Delirium']. Ned Tijdschr Geneeskd 2005;149:1027-32.

62. Jacobi J, Fraser GL, Coursin DB, et al. Clinical practice guidelines for the sustained use of sedatives and analgesics in the critically ill adult. Crit Care Med 2002;30:119-41.

63. Fraser North, Burnaby Hospital. Clinical practice guideline: delirium in the elderly. British Columbia: Fraser Health Authority, 2002.

64. Practice guideline for the treatment of patients with delirium. American Psychiatric Association. Am J Psychiatry 1999;156(5 Suppl):1-20.

65. Barr J, Kishman CP Jr, Jaeschke R. The methodological approach used to develop the 2013 Pain, Agitation, and Delirium Clinical Practice Guidelines for adult ICU patients. Crit Care Med 2013;41 (Suppl 1):S1-15.

66. Registered Nurses' Association of Ontario. Toolkit: implementation of best practice guidelines. 2nd edn. Toronto: Registered Nurses' Association of Ontario (RNAO), 2012. (cited 9 May 2016). http:// rnao.ca/bpg/resources/toolkit-implementation-best-practiceguidelines-second-edition.

67. O'Mahony R, Murthy L, Akunne A, et al. Guideline Development Group. Synopsis of The National Institute for Health and Clinical Excellence guideline for prevention of delirium. Ann Intern Med 2011;154(11):746-51.

68. Barr J, Fraser GL, Puntillo K, et al. Clinical practice guidelines for the management of pain, agitation, and delirium in adult patients in the Intensive Care Unit: executive summary. Am J Health Syst Pharm 2013;70(1):53-8.

69. Brajtman S, Wright D, Hogan DB, et al. Developing guidelines on the assessment and treatment of delirium in older adults at the end of life. Can Geriatr J 2011;14(2):40-50.

70. Lütz A, Spies C. [ICU delirium: Consequences for management of analgesia and sedation in the critically ill]. Anasthesiol Intensivmed Notfallmed Schmerzther 2011;46(9):568-72.

71. Sendelbach S, Guthrie PF, Schoenfelder DP. Acute confusion/ delirium. J Gerontol Nurs 2009;35(11):11-8.

72. Tropea J, Slee JA, Brand CA, et al. Clinical practice guidelines for the management of delirium in older people in Australia. Australas J Ageing 2008;27(3):150-6.

73. van der Weele GM, Olde Rikkert MG, Eizenga WH, et al. [Summary of the Dutch College of General Practitioners' practice guideline 'Delirium in elderly people']. Ned Tijdschr Geneeskd 2003;147 (20):965-9

74. van der Mast RC, Huyse FJ, Rosier PF. [Guideline 'Delirium'] Richtlijn 'Delirium'. Ned Tijdschr Geneeskd 2005;149(19):1027-32.

75. Potter J, George J. Guideline Development Group. The prevention, diagnosis and management of delirium in older people: concise guidelines. Clin Med (Lond) 2006;6(3):303-8.

76. Rapp CG, Mentes JC, Titler MG. Acute confusion/delirium protocol. $J$ Gerontol Nurs 2001;27(4):21-33. quiz 62-3.

77. American College of Critical Care Medicine of the Society of Critical Care Medicine, American Society of Health-System
Pharmacists, American College of Chest Physicians. Clinical practice guidelines for the sustained use of sedatives and analgesics in the critically ill adult. Am J Health Syst Pharm 2002;59(2):150-78.

78. Mudge AM, Maussen C, Duncan J, et al. Improving quality of delirium care in a general medical service with established interdisciplinary care: a controlled trial. Int Med Journal 2013;43 (3):270-7

79. Voellinger R, Stiefel F, Michaud L, et al. Implementation of guidelines on delirium in a general hospital: A before-after study of their impact on caregivers' knowledge and clinical skills. Schweizer Archiv fur Neurologie und Psychiatrie 2011;162(1):31-4.

80. Young LJ, George J. Do guidelines improve the process and outcomes of care in delirium? Age Ageing 2003;32(5):525-8.

81. Azermai M, Petrovic M, Elseviers MM, et al. Systematic appraisal of dementia guidelines for the management of behavioural and psychological symptoms. Ageing Res Rev 2012;11(1):78-86.

82. McSweeney M, Spies M, Cann CJ. Finding and evaluating clinical practice guidelines. Nurse Pract 2001;26(9):30, 33-4, 9 passim; quiz 47-9.

83. Alderson LJ, Alderson P, Tan T. Median life span of a cohort of National Institute for Health and Care Excellence clinical guidelines was about 60 months. J Clin Epidemiol 2014;67(1):52-5.

84. Becker M, Neugebauer EA, Eikermann M. Partial updating of clinical practice guidelines often makes more sense than full updating: a systematic review on methods and the development of an updating procedure. J Clin Epidemiol 2014;67(1):33-45.

85. Polus S, Lerberg P, Vogel J, et al. Appraisal of WHO guidelines in maternal health using the AGREE II assessment tool. PLOS ONE 2012;7(8):e38891

86. Bancos I, Cheng T, Prokop LJ, et al. Endocrine clinical practice guidelines in North America. A systematic assessment of quality. J Clin Epidemiol 2012;65(5):520-5.

87. Schildmann EK, Schildmann J, Kiesewetter I. Medication and monitoring in palliative sedation therapy: a systematic review and quality assessment of published guidelines. J Pain Symptom Manage 2015;49(4):734-46.

88. Gage L, Hogan DB. 2014 CCSMH Guideline update: The assessment and treatment of delirium. Toronto: Canadian Coalition for Seniors' Mental Health (CCSMH), 2014. (cited 3 May 2016). http://www.ccsmh.ca

89. Carthey J, Walker S, Deelchand V, et al. Breaking the rules: understanding non- compliance with policies and guidelines. $B M J$ 2011;343:d5283.

90. Brouwers MC, Kerkvliet K, Spithoff K. The AGREE Reporting Checklist: a tool to improve reporting of clinical practice guidelines. BMJ 2016;352:11152.

91. Brouwers MC, Kho ME, Browman GP, et al. Development of the AGREE II, part 1: performance, usefulness and areas for improvement. CMAJ 2010;182(10):1045-52.

92. Brouwers MC, Kho ME, Browman GP, et al. Development of the AGREE II, part 2: assessment of validity of items and tools to support application. CMAJ 2010;182(10):E472-8.

93. Makarski J, Brouwers MC. The AGREE Enterprise: a decade of advancing clinical practice guidelines. Implement Sci 2014;9:103.

94. Watine JC, Bunting PS. Mass colorectal cancer screening: methodological quality of practice guidelines is not related to their content validity. Clin Biochem 2008;41(7-8):459-66.

95. National Institute for Health and Care Excellence. Developing NICE guidelines: the manual. Manchester: National Institute for Health and Care Excellence, 2014. Section 9.3, P.181.

96. National Institute for Health and Care Excellence. Delirium: NICE quality standard 63. UK: National Institute for Health and Care Excellence, 2014. (cited 3 May 2016). guidance.nice.org.uk/qs63 